\title{
Cell cycle dynamics of NG2 cells in the postnatal and ageing brain
}

\author{
KONSTANTINA PSACHOULIA, FRANCOISE JAMEN ${ }^{1}$, KAYLENE M. YOUNG* \\ AND WILLIAM D. RICHARDSON*
}

\begin{abstract}
Oligodendrocyte precursors (OLPs or 'NG2 cells') are abundant in the adult mouse brain, where they continue to proliferate and generate new myelinating oligodendrocytes. By cumulative BrdU labelling, we estimated the cell cycle time $\mathrm{T}_{C}$ and the proportion of NG2 cells that is actively cycling (the growth fraction) at $\sim$ postnatal day 6 (P6), P6o, P240 and $P_{540}$. In the corpus callosum, $\mathrm{T}_{C}$ increased from $<_{2}$ days at $\mathrm{P} 6$ to $\sim 9$ days at $P 60$ to $\sim 70$ days at $\mathrm{P}_{240}$ and $P_{540}$. In the cortex, $\mathrm{T}_{C}$ increased from $\sim 2$ days to $>150$ days over the same period. The growth fraction remained relatively invariant at $\sim 50 \%$ in both cortex and corpus callosum - that is, similar numbers of mitotically active and inactive NG2 cells co-exist at all ages. Our data imply that a stable population of quiescent NG2 cells appears before the end of the first postnatal week and persists throughout life. The mitotically active population acts as a source of new oligodendrocytes during adulthood, while the biological significance of the quiescent population remains to be determined. We found that the mitotic status of adult NG2 cells is unrelated to their developmental site of origin in the ventral or dorsal telencephalon. We also report that new oligodendrocytes continue to be formed at a slow rate from NG2 cells even after P240 (8 months of age).
\end{abstract}

Keywords: NG2 cell, cell cycle, oligodendrocyte, corpus callosum, cerebral cortex, ageing, adult brain, PDGFRA, Cre recombinase, transgenic mice

\section{INTRDDUCTION}

Adult cells with the antigenic phenotype of oligodendrocyte precursors (OLPs) were first identified in the rat optic nerve and later in other parts of the adult mammalian central nervous system (CNS) (ffrench-Constant and Raff, 1986; Wolswijk and Noble, 1989; Engel and Wolswijk, 1996; Reynolds and Hardy, 1997; Chang et al., 2000; Horner et al., 2000; Reynolds et al., 2002). Like their perinatal counterparts, adult OLPs can generate either oligodendrocytes or GFAP+ 'type-2 astrocytes' in culture, depending on the composition of the culture medium. Also like perinatal OLPs, adult OLPs express the $\mathrm{NG}_{2}$ proteoglycan and the platelet-derived growth factor receptor (alpha subtype, PDGFRA) and can divide and migrate in vitro in response to PDGF, although their migration rate and cell cycle are both slower than perinatal OLPs (Wolswijk and Noble, 1989; Shi et al., 1998). Because of their obvious similarities to perinatal OLPs, the adult cells were generally presumed to be glial precursors that fulfil a homeostatic role in the adult CNS, replacing oligodendrocytes and possibly astrocytes that might die as a result of injury or disease or through normal wear and tear. PDGFRA/ NG2-expressing OLPs are distributed more-or-less uniformly throughout the adult brain and spinal cord. They are relatively abundant, comprising $\sim 5 \%$ of all cells in the mature CNS (Pringle et al., 1992; Dawson et al., 2003) (for review, see Nishiyama et al., 2009).

Study of adult OLPs started to take off with the development of antibodies against $\mathrm{NG}_{2}$ and so they came to be

Corresponding author:

William D. Richardson

Email: w.richardson@ucl.ac.uk known as 'NG2 cells' or 'NG2 glia'. The morphology of $\mathrm{NG}_{2}$ cells in vivo revealed that they are complex, ramified cells that contact neurons at synapses and nodes of Ranvier not the simple morphology one might expect of immature progenitor cells (Butt et al., 1999; Ong and Levine, 1999; Chang et al., 2000; Hamilton et al., 2009). These observations, together with the ubiquitous distribution of $\mathrm{NG}_{2}$ cells in both grey and white matter, have raised questions about the function of NG2 cells in the adult. Are they really glial precursors or differentiated cells that perform some essential physiological role in their own right? The latter view has been encouraged by the finding that postnatal NG2 cells express ligandand voltage-gated ion channels and receive synaptic input from neurons (Gallo et al., 1996; Bergles et al., 2000; Lin and Bergles, 2002, 2004; Lin et al., 2005; Karadottir et al., 2005; Salter and Fern, 2005). NG2 cells also form 'en-passant' glutamatergic synapses with unmyelinated axons in white matter tracts (Kukley et al., 2007; Ziskin et al., 2007). It has also been reported that some NG2 cells can fire action potentials in response to an initial depolarizing trigger (Chittajallu et al., 2004; Karadottir et al., 2008). While not all studies support this conclusion (e.g. Lin and Bergles, 2002), the possibility arises that $\mathrm{NG}_{2}$ cells might participate in neural processing, by sensing neuronal activity and reporting this activity to neighbouring neurons or glia through vesicular release.

Some NG2 cells continue to divide and incorporate bromodeoxyuridine (BrdU) during adulthood (Levison et al., 1999; Horner et al., 2000; Dawson et al., 2003; Lasiene et al., 2009). Since their number and distribution does not change much throughout life (Rivers et al., 2008), this implies that half of the daughters of each division, on average, must either differentiate (losing NG2 and PDGFRA immunoreactivity) or else die. 
Recently, several groups have followed the fates of dividing NG2 cells by 'Cre-lox' technology in adult transgenic mice. This approach relies on expressing a tamoxifen-inducible version of Cre recombinase (CreER) under transcriptional control of regulatory sequences associated with genes that are expressed specifically or preferentially in NG2 cells. When a Cre-conditional reporter transgene such as Rosaz6R-YFP is also present, brief administration of tamoxifen induces Cre recombination, activating the yellow fluorescent protein (YFP) reporter irreversibly in NG2 cells and all of their descendents. Using Pdgfra-CreER:Rosa26R-YFP transgenic mice our own laboratory showed that PDGFRA/NG2 cells generate many new myelin-forming oligodendrocytes in the adult corpus callosum and other white matter tracts (Rivers et al., 2008). Many new differentiated cells (PDGFRA- and $\mathrm{NG}_{2}$-negative) were also produced in the cortical grey matter. Although most of the latter did not make identifiable myelin sheaths, they did express the oligodendrocyte lineage marker SOX10 and the myelin protein $2^{\prime}, 3^{\prime}$-cyclic nucleotide phosphodiesterase (CNP), suggesting that they might be bona fide oligodendrocytes that make relatively few myelin sheaths compared to their counterparts in white matter. Alternatively, they might be a new type of non-myelinating oligodendrocyte lineage cell. An independent study using Olig2-CreER transgenic mice (in which transgene activity marked NG2 cells but not differentiated oligodendrocytes) came to similar conclusions (Dimou et al., 2008). There were some differences between the studies - for example, Rivers et al. (2008) found that small numbers of piriform projection neurons were produced during adulthood in addition to oligodendrocytes, whereas Dimou et al. (2008) found no evidence for neurogenesis. Nevertheless, both studies agreed that a major function of adult NG2 cells, like their perinatal counterparts, is to generate oligodendrocytes. This does not preclude the possibility that $\mathrm{NG}_{2}$ cells might perform another more 'physiological' role besides.

The fact that glutamate can influence the proliferation and differentiation of perinatal OLPs in culture suggests that their synaptic communication with unmyelinated axons in vivo might control the postnatal development of NG2 cells. Perhaps NG2 cells are 'listening in' to electrical activity, which at some threshold might trigger their myelination programme. This could ensure that only active circuits are myelinated and might even contribute to circuit plasticity during adulthood (Fields, 2008). Only around 30\% of axons are normally myelinated in the corpus callosum of 8-monthold mice, for example, so there is plenty of scope for de novo myelination in the adult CNS (Sturrock, 1980).

The idea that adult myelinogenesis might contribute to neural plasticity in humans is gaining ground. For example, it has been reported that extensive piano practice during childhood can cause long-term changes to the structure of white matter tracts, including parts of the corpus callosum, as revealed by magnetic resonance imaging (MRI) (Bengtsson et al., 2005). There is also an accumulating body of evidence that some measures of general cognitive ability correlate with white matter volume. For example, cognitive ability and white matter increase in parallel into the fourth decade of life and both decline thereafter (Bartzokis et al., 2001; Mabbott et al., 2006; Hasan et al., 2008; Ullen et al., 2008; Bartzokis et al., 2009; Zahr et al., 2009). The reasons behind these age-related changes are unknown but they could conceivably be related to changes in the ability of
NG2 cells to proliferate and generate new oligodendrocytes as the brain matures and ages.

$\mathrm{NG} 2$ cells are also thought to be crucial for remyelination following demyelinating injury or disease. For example, during cytotoxin-induced focal demyelination and subsequent re-myelination in mouse spinal cord, the dynamic behaviour of $\mathrm{NG}_{2}$ cells in and around the lesion suggests that they are the source of remyelinating oligodendrocytes (Keirstead et al., 1998; Reynolds et al., 2002; Watanabe et al., 2002; Dawson et al., 2003). The efficiency of remyelination following experimental demyelination decreases with age, which might be at least partly due to an age-related decline in the regenerative properties of $\mathrm{NG}_{2}$ cells (Sim et al., 2002). Therefore, NG2 cell function is probably crucial not only during normal healthy adulthood but also for repair following demyelinating insults to the CNS. It is therefore important to understand how and why the behaviour of $\mathrm{NG}_{2}$ cells changes with age. To this end we have investigated the cell cycle dynamics of NG2 cells and how this relates to the production of new oligodendrocytes in the mouse brain throughout life.

By cumulative BrdU labelling, we estimated cell cycle time $\left(T_{\mathrm{C}}\right)$ and the fraction of all NG2 cells that is actively engaged in the cell cycle (growth fraction) in the corpus callosum and cerebral cortex at ages ranging from P6 to $\mathrm{P}_{540}(\sim 18$ months). $T_{\mathrm{C}}$ increased dramatically from $\sim 2$ days at $\mathrm{P} 6$ to $\sim 70$ days at $\mathrm{P}_{240}$ and older. Unexpectedly, the growth fraction in both grey and white matter was approximately 50\% at all ages examined; that is, from soon after birth there appear to be separate populations of dividing and non-dividing NG2 cells. We had previously shown that oligodendrocyte lineage cells $\left(\mathrm{SOX}_{10}+\right)$ in the postnatal corpus callosum and cortex develop both from inwardly migrating (Gsh2-expressing) precursors that arise in the ventral telencephalon and local (Emx1-expressing) precursors in the cortical ventricular zone (VZ), in roughly equal proportions. We therefore asked whether the dividing and non-dividing subpopulations of $\mathrm{NG}_{2}$ cells have different developmental origins, by BrdU labelling in Gsh2-iCre:Rosa26R-GFP and Emx1-iCre: Rosa26R-GFP mice. We found that both dividing and nondividing NG2 cells were equally likely to be derived from the ventral or dorsal telencephalon. Thus, the mechanism that subdivides the $\mathrm{NG}_{2}$ population remains obscure. It will be interesting in future to determine whether the dividing and non-dividing subpopulations fulfil different roles in the postnatal CNS.

We also investigated the rate at which NG2/PDGFRA cells in Pdgfra-CreER ${ }^{T 2}:$ Rosa26R-YFP mice produced differentiated (YFP+, PDGFRA-negative) progeny. This rate decreased dramatically in the early postnatal period, as expected, and continued to decline thereafter. Thus, NG2 cell differentiation roughly parallels their rate of cell division. Nevertheless, they continue to divide slowly and generate small numbers of new oligodendrocytes even after 8 months of age.

\section{MATERIALS AND METHODS}

\section{Transgenic mice}

Homozygous Pdgfra-CreER ${ }^{T 2}$ BAC transgenic mice (Rivers et al., 2008) were crossed with homozygous Rosa26R-YFP Cre-conditional reporters (Srinivas et al., 2001) to generate 
double heterozygous offspring for analysis. Genotyping was by PCR as previously described (Rivers et al., 2008).

Heterozygous Gsh2-iCre and Emx1-iCre BAC transgenic mice (Kessaris et al., 2006) were separately crossed with homozygous Rosa26R-YFP or Rosa26R-GFP (Mao et al., 2001). Double-heterozygous offspring were identified by PCR using primers designed to detect iCre (forward 5'-GAG GGA CTA CCT CCT GTA CC, reverse 5'-TGC CCA GAG TCA TCC TTG GC), giving a $630 \mathrm{bp}$ product, and the modified Rosa locus (forward 5'-GCG AAG AGT TTG TCC TCA ACC, reverse 5'-GGA GCG GGA GAA ATG GAT ATG), giving either a $250 \mathrm{bp}$ or a $1100 \mathrm{bp}$ product for Rosa26R-YFP or Rosa26R-GFP, respectively.

\section{Tamoxifen administration}

Tamoxifen (Sigma) was dissolved at $40 \mathrm{mg} / \mathrm{ml}$ in corn oil by sonicating at $30^{\circ} \mathrm{C}$ for $1 \mathrm{~h}$. It was administered to Pdgfra-CreER ${ }^{T 2}:$ Rosa26R-YFP double heterozygous mice by oral gavage on 4 consecutive days (one dose of $300 \mathrm{mg}$ tamoxifen/kg body weight per day).

\section{BrdU cumulative label}

For cumulative labelling, BrdU was administered via the drinking water at a concentration of $1 \mathrm{mg} / \mathrm{ml}$. Alternatively, for early postnatal animals (P6; pups were aged between $\mathrm{P}_{4}$ and $\mathrm{P} 6$ at the beginning of the time course), BrdU was dissolved in phosphate-buffered saline (PBS) at $20 \mathrm{mg} / \mathrm{ml}$ and $30 \mu \mathrm{l}$ was injected subcutaneously every $3.5 \mathrm{~h}$.

\section{Tissue preparation and immunolabelling}

Mice were perfusion fixed with $4 \%(\mathrm{w} / \mathrm{v})$ paraformaldehyde (PFA) in PBS. Cryosections were collected and immunolabelled as described previously (Young et al., 2007). Briefly, $30 \mu \mathrm{m}$ coronal brain sections were labelled as floating sections with the following primary antibodies: rat monoclonal anti-PDGFRA (1:400; BD Pharmingen $\left.{ }^{\mathrm{TM}}\right)$, rabbit anti-GFP serum (1:60oo; AbCam), mouse monoclonal anti-BrdU (1:10; American Type Culture Collection, Manassas, VA), mouse monoclonal anti-CNPase (1:2000; Chemicon International). Secondary antibodies were goat anti-rat, donkey anti-rabbit or goat anti-mouse conjugated with Alexa Fluor-488, -568 or -647 (1:1000; Invitrogen). Cell nuclei were visualized by post-staining with Hoescht 33258 (1:1000; Sigma).

\section{Microscopy and cell counts}

All images were collected on an Ultraview confocal microscope (Perkin Elmer) as Z stacks with $1 \mu \mathrm{m}$ spacing, using standard excitation and emission filters for DAPI, FITC (Alexa Fluor 488), TRITC (Alexa Fluor 568) and Far Red (Alexa Fluor 647). Orthogonal views were produced using Volocity software (Perkin Elmer). For quantification, low magnification $(20 \times)$ non-overlapping fields were counted imaged along the length of the corpus callosum (eight fields) and throughout all layers of the medial (motor) cortex (12 fields). At least two sections from each of three mice were analysed for each time point.

\section{Estimation of cell cycle parameters}

For a homogeneous population of cycling cells, the fraction of cells that label with BrdU ('labelling index') is expected to increase linearly with the duration of BrdU exposure until all dividing cells are labelled (phase 1). After this the labelling index cannot increase further and a plateau is reached (phase 2). The rate at which cells incorporate BrdU is given by the slope $(m)$ of phase 1 . The maximum labelling index (phase 2 plateau value) is known as the 'growth fraction' ('GF'), which we express as a percentage of the total cell population. From these data we can calculate the length of the cell cycle $T_{\mathrm{C}}=\mathrm{GF} / m$ (Nowakowski et al., 1989; see Fig. 3). Since $T_{\mathrm{C}}$ depends on the reciprocal of $m$, the standard error (s.e. ${ }_{T c}$ ) is not symmetrical about the mean. However, for simplicity s.e.Tc is shown as \pm half of the full range, calculated as follows:

$$
\begin{aligned}
\text { s.e. }_{T c}=[ & \{(\mathrm{GF}+\text { s.e.GF }) /(m-\text { s.e. } m)\} \\
& -\{(\mathrm{GF}-\text { s.e.GF }) /(m+\text { s.e. } m)\}] / 2
\end{aligned}
$$

We subdivided our cumulative BrdU labelling plots into rising (phase 1) and plateau (phase 2 ) regions by an iterative process. We fitted the first three data points to a straight line by the method of least squares, then the first four data points and so on. The line with the smallest $R$ value was selected as the 'best-fit' for phase 1 and the remaining data points were assigned to the phase 2 plateau. Where three or more data points fell in the plateau region, they were analysed by analysis of variance (ANOVA). In no case were these significantly different from one another $(P>0.05)$. Comparisons were made between data sets using ANOVA and were considered significantly different at $P \leq 0.05$.

\section{RESULTS}

\section{The NG2 cell cycle slows dramatically with age}

We administered BrdU to wild-type mice continuously for up to 100 days starting on P6, P60, P240 (8 months) and P 540 (18 months). After various BrdU labelling times we doubleimmunolabelled coronal brain sections for PDGFRA and $\mathrm{BrdU}$ (Fig. 1) to visualize OLPs/NG2 cells that had undergone DNA replication during the labelling period. [We previously showed that $>99 \%$ of $\mathrm{NG}_{2}+$ non-vascular cells in the postnatal corpus callosum and cerebral cortex co-express PDGFRA (Rivers et al., 2008).] We counted cells in defined regions of the corpus callosum (Figs $1 \mathrm{a}-\mathrm{d}$ and 2) and medial cortex (Figs 1e-h and 2) in confocal micrographs (see Materials and Methods) and plotted BrdU labelling index versus labelling period. From these data we determined the cell cycle time $\left(T_{\mathrm{C}}\right)$ and fraction of OLPs that was cycling (growth fraction, GF) as a function of age (see Materials and Methods and Fig. 3).

In the corpus callosum, $T_{\mathrm{C}}$ increased from $<_{2}$ days at $\mathrm{P} 6$ to $\sim 70$ days at $\mathrm{P}_{240}$ and older (Fig. $3 \mathrm{~b}, \mathrm{c}$ ). In the cortex, $T_{\mathrm{C}}$ also increased steadily from $\sim 2$ days at $\mathrm{P} 6$ to $>_{100}$ days at $\mathrm{P}_{540}$. We cannot determine $T_{\mathrm{C}}$ in the $\mathrm{P}_{540}$ cortex with confidence because we do not know the GF; even at $\mathrm{P}_{540}+100$ days of BrdU labelling the labelling index still appeared to be on the increase (Fig. 1e). If we assume that $\mathrm{GF} \cong 0.4$ at $\mathrm{P}_{540}$, as it is at $\mathrm{P}_{240}$, then $T_{\mathrm{C}}\left(\mathrm{P}_{540}\right) \cong 170$ days. It is likely that most 
a
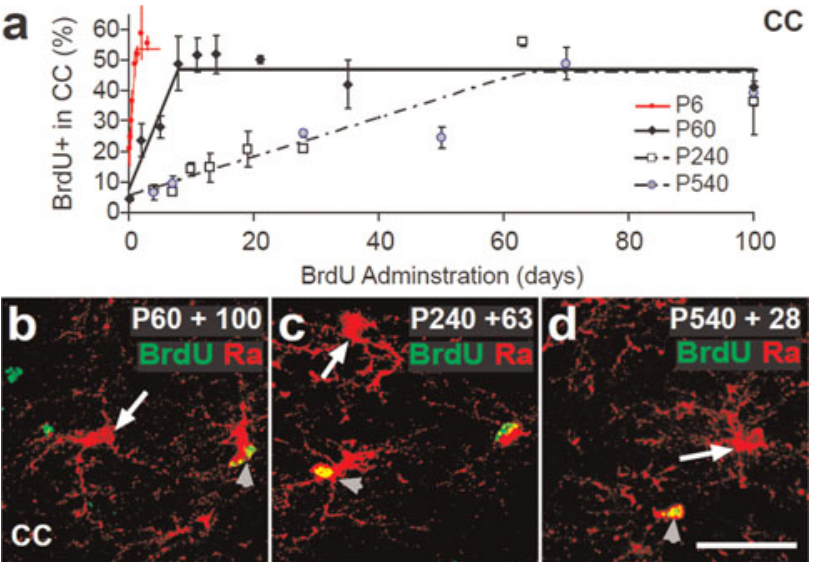

\section{e}
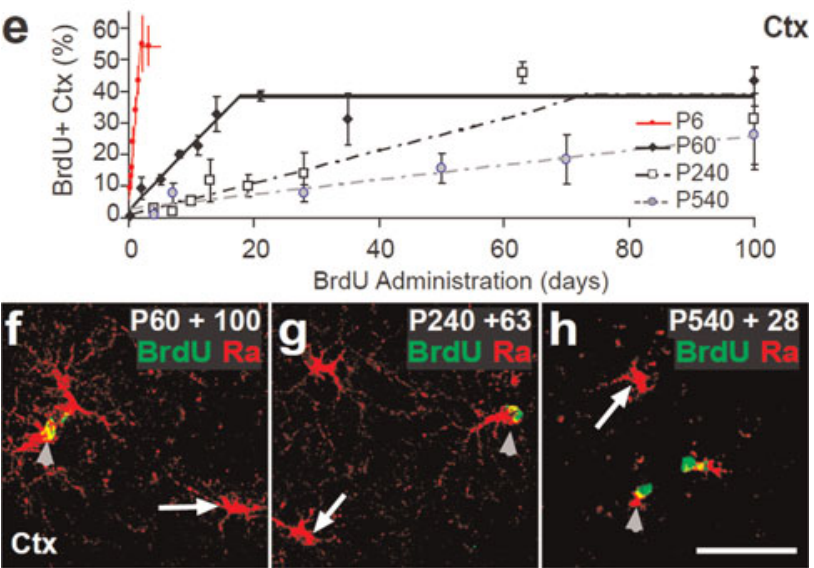

Fig. 1. NG2 cells continue to proliferate throughout postnatal life in the corpus callosum and cortex. BrdU was administered to mice by subcutaneous injection or via their drinking water (see Materials and Methods) for up to 100 days starting on $\sim$ P6, P6o (2 months), P240 (8 months) or $\mathrm{P}_{540}(18$ months). At various times after the start of BrdU administration, the number of BrdU+, PDGFRA+ cells was counted in the corpus callosum and cerebral cortex and expressed as a percentage of the total number of PDGFRA+ cells (a,e). BrdU+ (green), PDGFRA+ (red) NG2 cells could be detected readily in the grey $(b-d)$ and white $(f-h)$ matter at all ages. The point at which a plateau is reached indicates the fraction of the NG2 cell population that is actively cycling. Grey arrowheads indicate BrdU+, cycling $\mathrm{NG}_{2}$ cells and white arrowheads indicate non-cycling cells. CC, corpus callosum; Ctx, cortex; Ra, PDGFRA. Scale bars: b-d and $\mathrm{F}-\mathrm{H}, 20 \mu \mathrm{m}$.

of the variation in $T_{\mathrm{C}}$ results from how long cells remain resting in early G1.

When we examined the relationship between age and cell cycle length in the cortex, we found it to be linear (Fig. 3c). With every extra day after birth, the cell cycle increases by around one-third of a day. This relationship allows us to estimate $T_{\mathrm{C}}$ for any given postnatal age. In the corpus callosum there was not a simple linear relationship between age and $T_{\mathrm{C}}$ (Fig. 3 c); $T_{\mathrm{C}}$ reached its maximum around $\mathrm{P}_{240}$ and did not increase significantly after that.

\section{Dividing and non-dividing NG2 sub-populations in the postnatal brain}

In contrast to $T_{\mathcal{c}}$, GF was relatively invariant with age, $\sim 50 \%$ at all ages in both callosal white matter and in the cortical grey (Fig. 1a,e; Fig 3b). This implies that in the
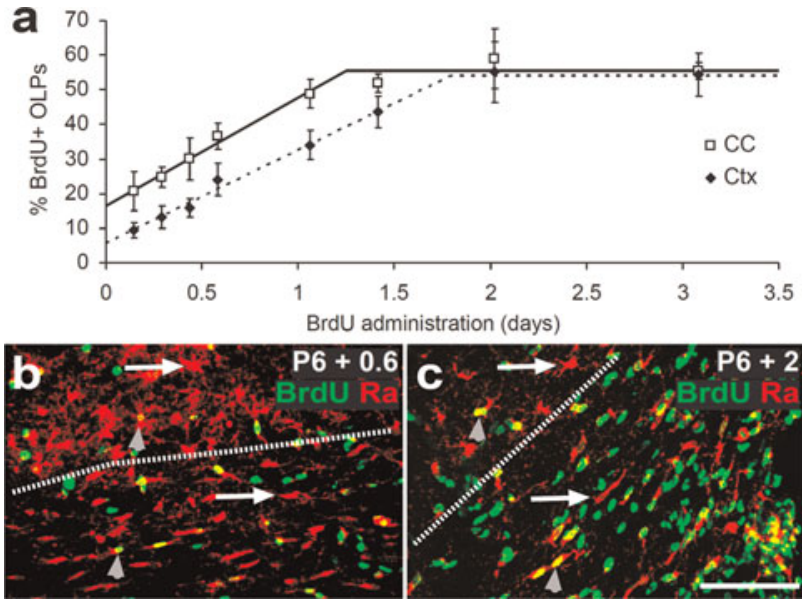

Fig. 2. Quiescent NG2 cells appear before the end of the first postnata week. BrdU was administered for $\sim 3$ days starting on P6 by repeated subcutaneous injections. (These data are the same as those shown in red in Fig. 1a,e.) At various times after the start of BrdU administration, BrdU+, PDGFRA + cells were counted in the corpus callosum and cortex and expressed as a percentage of the total number of PDGFRA+ cells (a). BrdU+ (green), PDGFRA + (red) NG2 cells could be detected readily in the grey and white matter at all BrdU labelling periods. Grey arrowheads indicate cycling, BrdU+ NG2 cells and white arrowheads non-cycling cells $(b, c)$. The white dashed line indicates the border between corpus callosum and cortical grey matter. CC, corpus callosum; Ctx, cortex; Ra, PDGFRA. Scale bar: b,c, $60 \mu \mathrm{m}$.

postnatal forebrain only around half of all NG2 cells are actively engaged in the cell cycle at any age, the other half being long-term quiescent. These separate dividing and quiescent populations are already present in the brain shortly after birth at $\mathrm{P}_{4}-\mathrm{P}_{7}$.

\section{Oligodendrocyte production declines in parallel with the NG2 cell cycle}

We previously showed that many new myelinating oligodendrocytes are formed in the corpus callosum during young adulthood (Rivers et al., 2008). In that study we treated Pdgra-CreER ${ }^{T 2}$ :Rosa26R-YFP mice with tamoxifen at $\mathrm{P}_{45}$ and followed the subsequent differentiation of labelled NG2 cells (YFP+, PDGFRA+) into oligodendrocytes (YFP+, SOX10+, PDGFRA-negative) over the following months. By this means we found that $\sim 29 \%$ of the myelin-forming oligodendrocytes present at $\mathrm{P}_{240}$ were formed after $\mathrm{P}_{45}$ (Rivers et al., 2008). To ask whether oligodendrocyte production continues after $\mathrm{P}_{240}$ we have now administered tamoxifen to $\mathrm{P}_{240}$ Pdgfra-CreER ${ }^{T 2}: R o s a_{2} 6 R-Y F P$ mice and have followed the subsequent appearance of differentiated YFP+ progeny for up to 100 days post-tamoxifen $\left(\mathrm{P}_{240}+100\right)$. We first determined that $\sim 48 \%$ of all PDGFRA + cells became YFPlabelled following tamoxifen administration (Fig. $4 \mathrm{a}-\mathrm{c}$ ) very similar to the fraction that became labelled after tamoxifen administration at $\mathrm{P} 45$ (Rivers et al., 2008). We detected no difference in the proportion of YFP-labelled cells in the corpus callosum versus the cortex. Maximal YFP-labelling of NG2 cells was achieved by 10 days after the first dose of tamoxifen (6 days after the final dose) (Fig. 4a). We previously found that maximal labelling in $\mathrm{P}_{45}$ mice took $\sim 8$ days (Rivers et al., 2008), which might indicate that tamoxifen is 
a

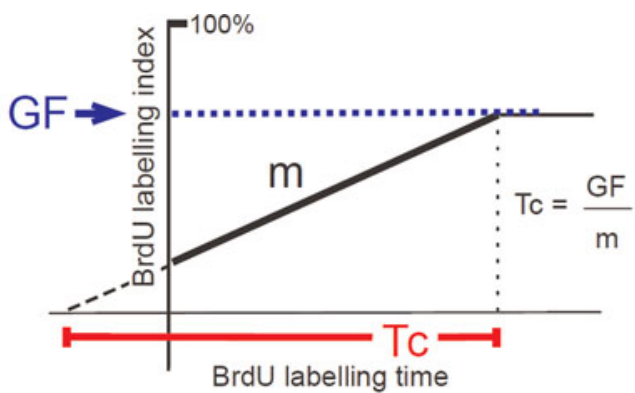

\begin{tabular}{|c|c|c|c|c|c|}
\hline \multirow{2}{*}{\multicolumn{2}{|c|}{ b }} & \multicolumn{4}{|c|}{ Postnatal Age (days) } \\
\hline & & 6 & 60 & 240 & 540 \\
\hline \multirow{3}{*}{$\begin{array}{l}\mathrm{C} \\
\mathrm{C}\end{array}$} & GF & $0.54 \pm 0.02$ & $0.47 \pm 0.02$ & $0.46 \pm 0.06$ & $0.45 \pm 0.03$ \\
\hline & $\mathrm{m}$ & $0.31 \pm 0.02$ & $0.05 \pm 0.01$ & $0.006 \pm 0.001$ & $0.006 \pm 0.001$ \\
\hline & Tc & $1.7 \pm 0.2$ & $9 \pm 2$ & $72 \pm 21$ & $75 \pm 18$ \\
\hline \multirow{3}{*}{$\begin{array}{l}c \\
t \\
x\end{array}$} & GF & $0.55 \pm 0.03$ & $0.38 \pm 0.02$ & $0.39 \pm 0.03$ & - \\
\hline & $\mathrm{m}$ & $0.27 \pm 0.01$ & $0.021 \pm 0.002$ & $0.0051 \pm 0.001$ & $0.0023 \pm 0.0005$ \\
\hline & Tc & $2 \pm 0.2$ & $18 \pm 3$ & $76 \pm 28$ & $170 \pm 54$ \\
\hline
\end{tabular}

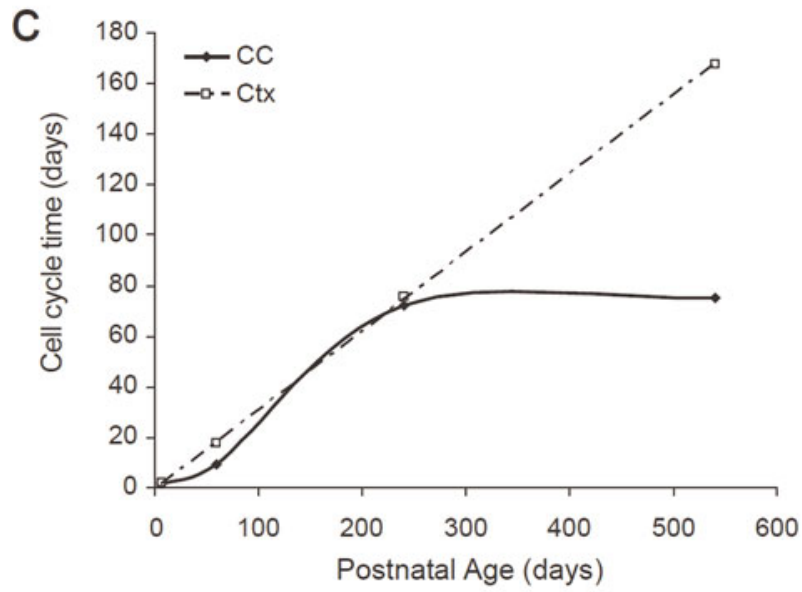

Fig. 3. The NG2 cell cycle slows down during postnatal life. BrdU was administered to mice via their drinking water starting on P6, P6o, P240 or $\mathrm{P}_{540}$ and the fraction (percentage) of PDGFRA+ NG2 cells that was BrdU+ was plotted versus the BrdU labelling period. (a) Calculation of cell cycle time $\left(T_{\mathrm{C}}\right)$. The gradient $(m)$ of the linear rising part of the graph was determined by the method of least squares (see Materials and Methods). The labelling index at plateau is the fraction of the population that is actively cycling (the growth fraction, GF). If the whole population were cycling GF would be $100 \%$; in our experiments GF was closer to $50 \%$. (b) Table of GF, $m$ and $T_{\mathrm{C}}$ for NG2 cells in the corpus callosum and cortex at the ages examined. (c) In the cortex there was a linear relationship between age and $T_{\mathrm{C}}$. In the corpus callosum $T_{\mathrm{C}}$ reached a plateau after $\sim \mathrm{P}_{240}$. CC, corpus callosum; Ctx, cortex.

metabolized to the biologically active form (4-hydroxy tamoxifen) more rapidly in younger mice or that accumulation of YFP takes longer in older cells. Nevertheless, at early times (10 days) post-tamoxifen the great majority of YFP-labelled cells in both white and grey matter were also PDGFRA+, as predicted (Fig. 4 b,c).

The great majority of YFP+ cells continued to co-label for PDGFRA at all time points examined post-tamoxifen (Fig. 4d,e). However, there was a slow but steady accumulation of YFP+, PDGFRA-negative cells in the grey and a
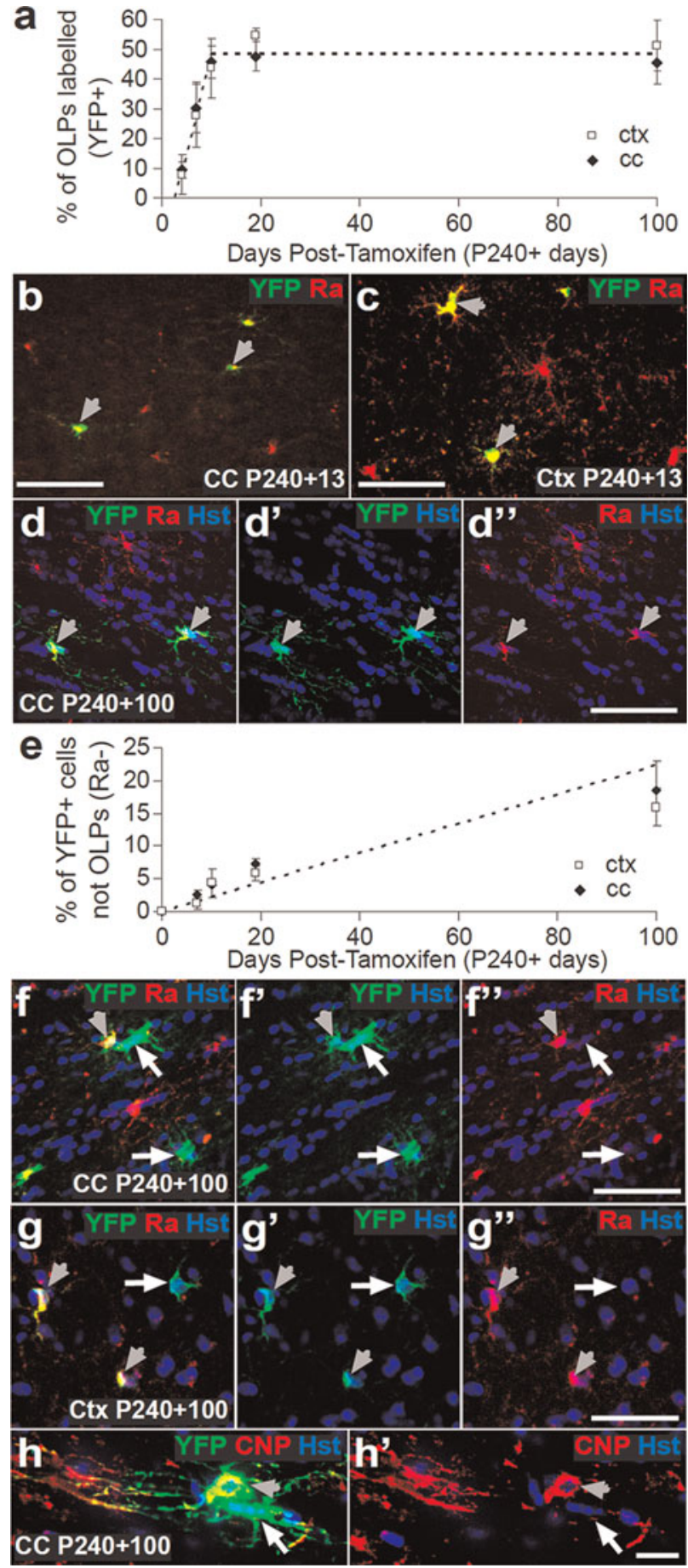

Fig. 4. NG2 cells continue to produce oligodendrocytes after 8 months of age. To trace the fate of $\mathrm{NG}_{2}$ cells in the mature brain, tamoxifen was administered to Pdgfra-CreER ${ }^{T 2}$ :Rosa26R-YFP mice starting on P240. (a) The proportion of PDGFRA+ cells that became YFP-labelled is plotted against time post-tamoxifen. Within $\sim 10$ days post-tamoxifen $\sim 45 \%$ of PDGFRA+ (red) cells in the corpus callosum (b) and cortex (c) become stably labelled with YFP (green). Tracing the fate of YFP+ cells revealed that the great majority of YFP+ cells remained undifferentiated (PDGFRA+), even 100 days post-tamoxifen $\left(\mathrm{P}_{240}+100\right)(\mathrm{d})$. The proportion of YFP+ cells that were differentiated (PDGFRA-negative) increased slowly with time (e). YFP+, PDGFRA-negative cells were generated in both the corpus callosum (f) and cortex (g). (h) YFP+ cells (green) with the morphology of oligodendrocytes were found to co-stain for the differentiated oligodendrocyte marker CNPase (red). Grey arrowhead indicates a YFP+, PDGFRA+ NG2 cell, and white arrow indicates a YFP+, PDGFRA-negative oligodendrocyte. CC, corpus callosum; Ctx, cortex; Ra, PDGFRA; Hst, Hoescht 33258. Scale bars: b-d, $35 \mu \mathrm{m}$; f,g, $30 \mu \mathrm{m}$; h, $10 \mu \mathrm{m}$. 
white matter so that by $\mathrm{P} 240+100$ approximately $18 \%$ of YFP+ cells in both corpus callosum and cortex were PDGFRA-negative, differentiated cells (Fig. 4e-g). The YFP+, PDGFRA-negative cells in the corpus callosum had the appearance of oligodendrocytes (Fig. 4f) and they co-immunolabelled for CNPase, a marker of differentiated oligodendrocytes (Fig. 4h). This confirmed that new oligodendrocytes continue to be generated from $\mathrm{NG}_{2}$ cells even after 8 months of age.

\section{Mitotic status of $\mathrm{NG}_{2}$ cells is unrelated to their developmental site of origin}

We previously traced the embryonic origins of oligodendrocyte lineage cells (SOX10+) in the forebrain by Cre-lox fate mapping and found that they have multiple developmental origins in the $\mathrm{VZ}$ of the ventral and dorsal telencephalon (Kessaris et al., 2006). The first OLPs were generated in the ventral telencephalon around embryonic day 12.5 (E12.5), from the VZ of the medial ganglionic eminence (MGE). Subsequently, they arose more dorsally in the $\mathrm{VZ}$ of the lateral ganglionic eminence (LGE) and ultimately (after birth) from the cortical VZ (Kessaris et al., 2006). The MGE- and LGE-derived OLPs migrated widely throughout the developing forebrain including the cerebral cortex, whereas those derived from the cortical VZ remained within the cortex. After birth, the MGE-derived population declined rapidly within the cortex, for unknown reasons, so that the postnatal cortex and corpus callosum become populated by a roughly equal mixture of LGE- and cortex-derived oligodendrocyte lineage cells. It seemed possible that these ventrally and dorsally derived populations might correspond in some way to the dividing and quiescent $\mathrm{NG}_{2}$ cell populations identified in the present study. We therefore set out to determine whether there was a correlation between the developmental origin of NG2 cells and their ability to incorporate BrdU in the adult.

As in our previous study (Kessaris et al., 2006), we visualized LGE- or cortex-derived cells in Gsh2-iCre:Rosa26R-GFP or Emx1-iCre:Rosa26R-GFP mice, respectively. At P6o we immunolabelled forebrain sections for PDGFRA and GFP (Fig. 5a,b) to identify OLPs/NG2 cells that had originated from the LGE or cortex. We confirmed that PDGFRA+ cells from each region were intermingled and were present in similar proportions (Fig. 5a-e). In both corpus callosum and cortex there was a modest fraction of $\mathrm{NG}_{2}$ cells (10-20\%) that appeared not to be derived from either ventral or dorsal forebrain, consistent with our previous data. We think these might be derived from the diencephalon (Kessaris et al., 2006).

We administered BrdU to P6o mice via their drinking water for 6 or 35 days, and then immunolabelled brain sections for GFP, PDGFRA and BrdU. We counted triplelabelled cells in the corpus callosum and cortex and expressed these as a percentage of the total number of (GFP+, PDGFRA +) cells in the same region (Fig. $5 \mathrm{f}-\mathrm{i}$ ). The fraction of (GFP+, PDGFRA+) cells that incorporated BrdU was similar in both Gsh2-iCre:Rosa26R-GFP and Emx1-iCre: Rosa26R-GFP animals and each was representative of the PDGFRA+ cell population as a whole (Fig. $5 \mathrm{f}-\mathrm{i}$ ). We conclude that developmental origin has no influence on the proliferative behaviour of $\mathrm{NG}_{2}$ cells.

\section{DISCUSSIDN}

We have studied the cell cycle dynamics of NG2 cells in the postnatal forebrain and reached the following conclusions: (1) cell cycle time increases dramatically from $\sim 2$ days to $>_{70}$ days in the corpus callosum $\left(>_{150}\right.$ days in cortex) between $\sim$ P6 to $\mathrm{P} 240$; (2) oligodendrocyte differentiation continues throughout adulthood, but the rate of oligodendrocyte production declines in parallel with the rate of precursor cell division; (3) there are two distinct populations of NG2 cells, a mitotically active population and a separate quiescent population; (4) the subdivision into dividing and non-dividing $\mathrm{NG}_{2}$ cell populations is not related to their developmental origins in either the ventral or dorsal telencephalon.

A recent study of surgical tissue has provided evidence that, at any one time, a substantial fraction of cycling adult human $\mathrm{NG}_{2}$ cells is in the early $\mathrm{G}_{1}$ phase of the cycle (Geha et al., 2009). This study exploited the fact that the cell-cycle-related antigen Ki-67 (Mib-1) is detectable in cells from late $\mathrm{G}_{1}$ through to M-phase but not in early $\mathrm{G}_{1}$, whereas the minichromosome maintenance protein-2 $(\mathrm{Mcm}-2)$ is expressed at all stages of the cycle. They found that cycling cells identified by either $\mathrm{Ki}-67$ or $\mathrm{Mcm}-2$ in the cortical grey or white matter all co-expressed $\mathrm{NG}_{2}$ and OLIG2. However, Mcm-2+ cells outnumbered Ki-67+ cells $\sim 3$-fold, consistent with a long cell cycle and an extended $\mathrm{G} 1$. We ourselves found that $\sim 29 \%$ of PDGFRA/NG2 cells in the P6 mouse corpus callosum were $\mathrm{Ki}-67+$, dropping to $\sim 15 \%$ at P6o (three sections from one animal in each case). Thus, the Ki-67 labelling index does not match the growth fraction estimated by cumulative BrdU labelling ( $\sim 50 \%$ at all ages) but it does decline in parallel with the increase in the length of the cell cycle - as expected if the cell cycle slows down because the duration of $\mathrm{G}_{1}$ increases.

The mitotically active NG2 cells function as bona fide OLPs but what is the function of the quiescent NG2 cells? Two categories of NG2 cells in the $\mathrm{P}_{7}$ cerebellar white matter have been reported on the basis of their electrical properties; one class expressed voltage-gated sodium and potassium channels and fired action potentials in response to a depolarizing stimulus, whereas the other class did not express voltage-gated channels and displayed a linear voltage-current relationship (Karadottir et al., 2008). These two types of NG2 cell were also identified in the corpus callosum (Karadottir et al., 2008). Intriguingly, the two electrophysiological subtypes of $\mathrm{NG} 2$ cell were found in approximately equal proportions, as are our dividing and non-dividing subtypes. One possibility is that, during development, all newly generated NG2 cells attach to unmyelinated axons, some of which fire action potentials and deliver a mitogenic signal to their associated NG2 cells. These NG2 cells consequently divide, renewing themselves and producing myelinating oligodendrocytes. The other NG2 cells are associated with axons that never fire, or do not fire above a sufficient threshold, so these cells are destined to remain mitotically inactive (Fig. 6). They might also lose their expression of voltage-gated ion channels, rendering them electrically passive. These might contribute in some other way to the neuronal circuitry - for example, they might perform some essential homeostatic function at nodes of Ranvier or at neuron-neuron synapses (Butt et al., 2002). This model implies that the spiking sub-class of $\mathrm{NG}_{2}$ cells might correspond to our mitotically active fraction. Against 

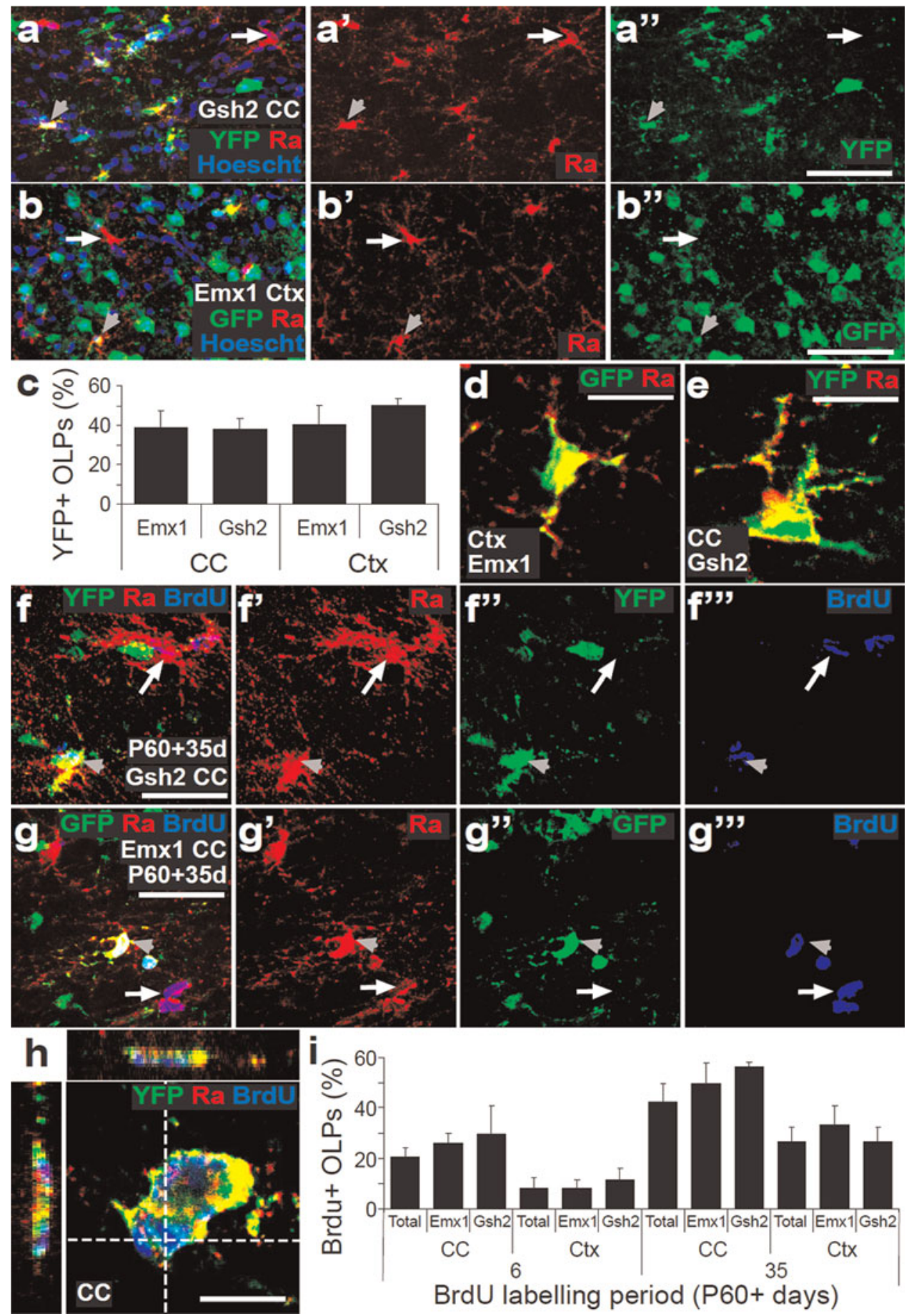

Fig. 5. NG2 cells derived from both the dorsal and ventral VZ contribute to both the cycling and non-cycling populations. By crossing Gsh2-iCre or Emx1-iCre transgenic mice with Cre-sensitive Rosa26R-GFP reporter mice, we were able to trace GFP+ (green), PDGFRA+ (red) NG2 cells that originated from either the embryonic LGE/MGE or the cortical VZ, respectively $(\mathrm{a}, \mathrm{b})$. (c) Numbers of GFP+, PDGFRA+ cells in the corpus callosum or cortex (three sections from each of six mice) were expressed as a percentage of all PDGFRA+ cells in the same region. Gsh2- and Emx1-derived NG2 cells were found in approximately equal numbers in both corpus callosum and cortex (d,e). To determine whether Gsh2- and/or Emx1-derived NG2 cells were dividing, BrdU was administered via the drinking water for 6 or 35 days starting on P6o and brain sections were triple immunolabelled for BrdU (blue), PDGFRA (red) and GFP (green) (f,g). GFP+, PDGFRA+ cells were scored as BrdU-positive or -negative by examining confocal images with orthogonal projections (h). Numbers of BrdU+, GFP+, PDGFRA + cells in corpus callosum and cortex were expressed as a percentage of all GFP+, PDGFRA+ cells in the same area. Both Gsh2-and Emx1-derived PDGFRA/NG2 cells contributed approximately equally to the cycling and non-cycling sub-populations. Grey arrowheads indicate (GFP+, PDGFRA+) double-positive (a,b) or (BrdU+, GFP+, PDGFRA+) triple-positive (f,g) cells. White arrows indicate a PDGFRA+ single-positive (a,b) or (GFP+, PDGFRA+) double-positive (f,g) cell. CC, corpus callosum; Ctx cortex, Ra, PDGFRA. Scale bars: a,b, $40 \mu \mathrm{m}$; d-e, $10 \mu \mathrm{m}$; f,g, $17 \mu \mathrm{m}$; h, $6 \mu \mathrm{m}$.

this, Kukley et al. (2008) found that some NG2 cells had synapses and sodium channels, whether or not they expressed PCNA, implying that both cycling and non-cycling cells are electrically active. Also, not all workers agree that NG2 cells can fire action potentials (Lin and Bergles, 2002), so these ideas need further scrutiny.

Are the non-dividing $\mathrm{NG}_{2}$ cells permanently post-mitotic, or can they ever re-enter the cell cycle? It seems possible that 


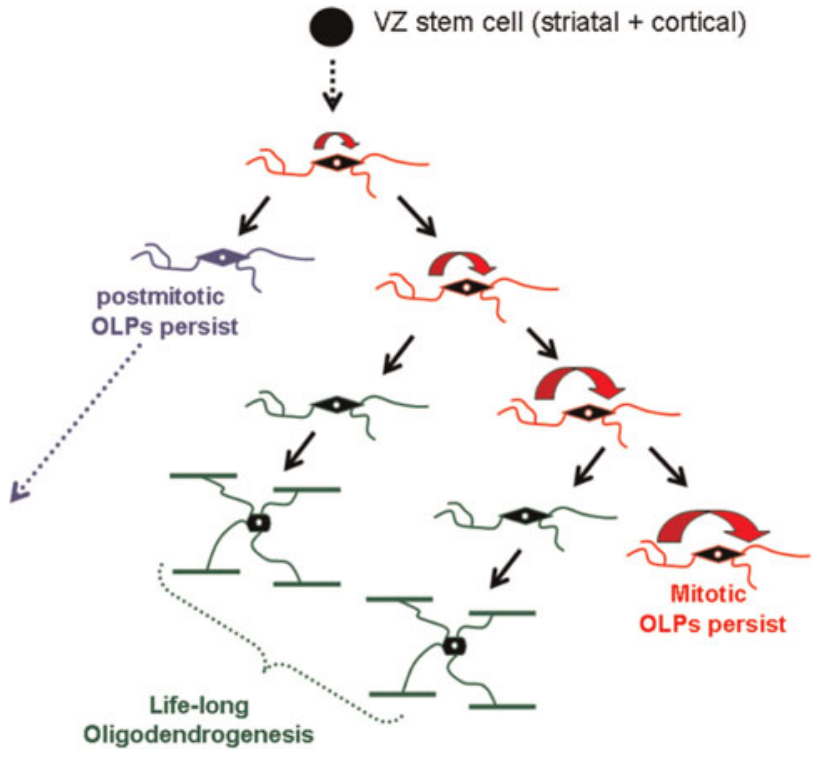

Fig. 6. The birth and behaviour of NG2 glia. From data presented in this paper and Kessaris et al. (2006), we conclude that adult forebrain OLPs/ $\mathrm{NG} 2$ cells are initially derived from embryonic VZ stem cells located in both the dorsal (cortical) and ventral (LGE/MGE) telencephalon. In this paper we show that their embryonic origin does not have any bearing on their mitotic activity as adult NG2 cells. A population of quiescent $\mathrm{NG}_{2}$ cells, comprising approximately half of all $\mathrm{NG}_{2}$ cells, appears some time before the end of the first postnatal week and persists throughout life. The function of these cells is unknown. The other half of the $\mathrm{NG}_{2}$ cell population remains in cycle throughout life, although their cell cycle length increases with age (e.g. from $\sim 2$ days at P6, to $\sim 70$ days at 8 months and $>_{150}$ days at 18 month in the cortex). One major function of the proliferating OLPs is to generate new oligodendrocytes throughout life. However, the rate of oligodendrogenesis slows progressively with age, roughly in parallel with the decelerating cell cycle.

they do not divide under normal conditions because, once the BrdU labelling index reached plateau, there was no sign of any further increase even after a very long labelling period. For example, at $\mathrm{P} 60$ the BrdU labelling index in the corpus callosum reached $40-50 \%$ after $\sim 8$ days $(\sim 20$ days in cortex $)$ but did not increase further than that even after 100 days of continuous BrdU exposure (until P160). At earlier (P6) and later ( $\mathrm{P}_{240)}$ ages the steady-state labelling index was very similar $(\sim 50 \%)$; so it seems that a stable non-dividing subpopulation forms during late embryogenesis or during the first few postnatal days and persists for many months.

An alternative scenario that might be consistent with our data is that there is a continuous flow of cells: non-dividing $\mathrm{NG}_{2}$ cell $\rightarrow$ dividing NG2 cell $\rightarrow$ differentiated oligodendrocyte. However, to maintain the NG2 cell population this would require continuous replacement of non-dividing NG2 cells from some other source. Where would they come from? A potential source might be the adult subventricular zone (SVZ), which has been shown to generate some glial precursors and oligodendrocytes during adulthood (Levison et al., 1999; Menn et al., 2006). However, we previously showed by Cre-lox fate mapping that only a tiny proportion of oligodendrocyte lineage cells in the adult corpus callosum are SVZ derived, the main source being the pre-existing population of adult NG2 cells (Rivers et al., 2008). Furthermore, SVZ precursors are themselves a mitotically active population, so, under the conditions of our cumulative labelling experiments, SVZ-derived NG2 cells would still be BrdU+. It therefore seems most likely that the quiescent NG2 cell population is stable long-term. The dividing population of NG2 cells also seems to be stable because although the cells divide more slowly with age they do not exit the cell cycle - i.e. the growth fraction does not decline with age. Our growth fraction measurements are in keeping with a previous report that the growth fraction (defined by PCNA immunolabelling) of $\mathrm{P}_{7}-\mathrm{P}_{12}$ mouse hippocampal NG2 cells is also close to $50 \%$ (Kukley et al., 2008). Moreover, Keirstead et al. (1998) found that $\sim 50 \%$ of NG2 cells in the adult rat spinal cord were resistant to killing by $\mathrm{X}$-irradiation, suggesting that they were dividing very slowly or not at all.

Whether the non-dividing NG2 cells are intrinsically incapable of division, or else are inhibited from doing so by their local environmental, is another question. It will be interesting, for example, to see if the growth fraction can be increased by culturing dissociated cells in saturating concentrations of mitogens (e.g. PDGF), which would be expected to override environmental regulation. It will also be informative to discover whether the cell cycle of older NG2 cells can be accelerated by culturing in PDGF or other mitogens. We showed previously that the cell cycle time of OLPs in the embryonic mouse spinal cord increases from $\sim 30 \mathrm{~h}$ to $70-$ $100 \mathrm{~h}$ between $\mathrm{E}_{13}$ and E17, but that both E13 and E17 cells can accelerate their cycle to $\sim 20 \mathrm{~h}$ when cultured in medium containing saturating PDGF-AA. This demonstrated that slowing of the OLP cell cycle during late embryogenesis results from a change in their mitogenic environment, not a shift in the intrinsic properties of the cells (van Heyningen et al., 2001). Transgenic mice engineered to over-express PDGF-A in the CNS have an increased number of NG2 cells during adulthood (Woodruff et al., 2004) as well as in the embryo (van Heyningen et al., 2001), suggesting that PDGF-AA is a critical mitogen for OLPs/NG2 cells throughout life. It is likely that PDGF acts in concert with other mitogenic stimuli including electrical stimulation; for example, there is evidence that proliferation of OLPs in the perinatal rat optic nerve depends on electrical activity of retinal ganglion cell axons, one effect of which might be to stimulate release of PDGF from astrocytes within the nerve (Barres and Raff, 1993). The fact that NG2 cells receive synaptic input from axons, together with previous evidence that the neurotransmitter glutamate can inhibit proliferation and differentiation of $\mathrm{OLP} / \mathrm{NG}_{2}$ cells in culture, suggests that neurotransmitter release at axon-glial synapses might directly or indirectly influence the NG2 cell cycle and the myelination programme.

Dividing NG2 cells in white matter tracts generates new myelinating oligodendrocytes. Since the number of $\mathrm{NG} 2$ cells stays relatively constant during the first year of life (Rivers et al., 2008), it follows that half of the daughters of cell divisions must either differentiate or die. For example, at $\mathrm{P}_{45}$ the cell cycle time in the corpus callosum is $\sim 7.5$ days (extrapolating from the data in Fig. 3 ), so it will take $\sim 15$ days (two cell cycles) for that half of the NG2 cells that is dividing to generate a number of differentiated cells equal to the starting population of NG2 cells. Put another way, the fraction of YFP + cells that is differentiated (therefore PDGFRA-negative) 15 days after administering tamoxifen to P45 Pdgfra-CreER ${ }^{T 2}:$ Rosa26R-YFP mice is predicted to be $50 \%$. At 14 days post-tamoxifen the predicted fraction is $\sim 48 \%$, which is close to experiment $(\sim 45 \%)$, so it appears that there is rather little death of newly differentiated cells in the 14 days after $\mathrm{P}_{45}$. A similar calculation for $\mathrm{P}_{240}$ 
$\left(T_{\mathrm{C}}=73 \pm 12\right.$ days) predicts that at 100 days post-tamoxifen $41 \pm 4 \%$ of YFP + cells should be PDGFRA negative. The observed value in this case was only $\sim 18 \%$, suggesting that less than half of the differentiated progeny of $\mathrm{NG}_{2}$ cells survive long-term between $\mathrm{P}_{240}$ and $\mathrm{P}_{340}$. Nevertheless, the rate of oligodendrocyte production in the corpus callosum roughly follows the rate of $\mathrm{NG}_{2}$ cell division, as expected; the cell cycle slows down $\sim 10$-fold between $\mathrm{P}_{45}$ and $\mathrm{P}_{240}$ and the rate of oligodendrocyte production slows $\sim 20$-fold in the same period. The same principle applies in the cortex (data not shown), although both cell division and production of YFP+, PDGFRA-negative cells are slower in the cortex than in the corpus callosum at most ages. Note that our estimate of $T_{\mathrm{C}}$ in 8 -month-old mice ( $\sim 73$ days) is in line with long-term retroviral tracing experiments that indicate an oligodendroglial cell doubling time in the 3-8-month-old rat cortex of around 3 months (Levison et al., 1999). An age-related increase in the cell cycle of OLPs in the mouse spinal cord was also noted by Lasiene et al. (2009). These authors also observed that the $\mathrm{NG}_{2}$ cell cycle started to speed up again in aged mice ( 21 months of age), but we did not observe this phenomenon in the forebrain of 18-month-old animals in this study.

Following experimental demyelination in rodents, the number of $\mathrm{NG}_{2}$ cells in and around lesions and the local BrdU labelling index both increase, indicating that the $\mathrm{NG}_{2}$ cell cycle speeds up in response to demyelination (Keirstead et al., 1998; Redwine and Armstrong, 1998; Levine and Reynolds, 1999; Watanabe et al., 2002). What causes the cell cycle to speed up? It is possible, for example, that mitogenic factors are released from naked axons or that loss of myelin somehow triggers mitogen release from nearby cells such as astrocytes. Redwine and Armstrong (1998) found increased PDGF-A immuno-reactivity in reactive astrocytes following $\mathrm{MHV}$-induced demyelination. Also, remyelination was enhanced in the corpus callosum of cuprizone-treated transgenic mice engineered to over-express PDGF-A in astrocytes (Vana et al., 2007). These observations suggest that astrocytederived PDGF might be involved in the mitogenic response of NG2 cells to demyelination. Fibroblast growth factor (FGF) might also be involved because NG2 cells express FGF receptors and up-regulate them following experimental demyelination (Redwine and Armstrong, 1998; Fortin et al., 2005; Redwine et al., 1997). Adult NG2 cell division in culture can be accelerated by a combination of PDGF and glial growth factor (GGF2, a soluble Neuregulin-1 isoform) (Shi et al., 1998). Thus, manipulating a range of growth factor signalling pathways might be useful in the context of enhancing remyelination by endogenous $\mathrm{NG}_{2}$ cells in demyelinating diseases like multiple sclerosis, as well as in other forms of injury with myelin involvement (McTigue and Tripathi, 2009). Note that even in demyelinated lesions the distinction between the cycling and non-cycling NG2 cell populations seems to be maintained and only the cycling population contributes to repair (Keirstead et al., 1998).

The age-related reduction in the proliferative rate of $\mathrm{NG}_{2}$ cells and the corresponding reduction in the rate of production of new oligodendrocytes could play an important role in the normal ageing process. For example, it is becoming clear that white matter volume starts to decline in humans after the fourth decade of life and that this white matter loss correlates with general deterioration of cognitive and motor ability. It could be that myelinating oligodendrocytes have a finite lifetime and, beyond this, the rate of new oligodendrocyte production cannot keep pace with accelerating oligodendrocyte loss. If so, finding ways to maintain $\mathrm{NG}_{2}$ cells in a more proliferation-competent state might help maintain white matter integrity and slow down age-related mental decline.

\section{ACKNDWLEDGEMENTS}

We thank our colleagues in the WIBR for helpful comments and discussion, and Ulla Dennehy and Marta Muller for technical support. We also thank carlos Parras and Hioko Nakatani (Hôptal de la Pitié-Salpêtrière, Paris) for helpful discussions and for exchange of data and materials. KMY is the recipient of an Alzheimer's Society Collaborative Career Development Award in Stem Cell Research. K.P. has a studentship from the UK Medical Research Council. The work was also supported by programme grants from the Medical Research Council and The Wellcome Trust.

\section{Statement of interest}

'Cycling and non-cycling populations of NG2 cells in the postnatal mouse brain' by Psachoulia, K., Jamen, F., Young, K.M. and Richardson, W.D.

There is no conflict of interest.

\section{REFERENCES}

Barres B.A. and Raff M.C. (1993) Proliferation of oligodendrocyte precursor cells depends on electrical activity in axons. Nature 361, 258-260.

Bartzokis G., Beckson M., Lu P.H., Nuechterlein K.H., Edwards N. and Mintz J. (2001) Age-related changes in frontal and temporal lobe volumes in men: a magnetic resonance imaging study. Archives of General Psychiatry 58, 461-465.

Bartzokis G., Lu P.H., Tingus K., Mendez M.F., Richard A., Peters D.G. et al. (2009) Lifespan trajectory of myelin integrity and maximum motor speed. Neurobiology of Aging, Epub in advance of print. doi:10.1016/j.neurobiolaging.2008.08.01.

Bengtsson S.L., Nagy Z., Skare S., Forsman L., Forssberg H. and Ullen F. (2005) Extensive piano practicing has regionally specific effects on white matter development. Nature Neuroscience 8, 1148-1150.

Bergles D.E., Roberts J.D., Somogyi P. and Jahr C.E. (2000) Glutamatergic synapses on oligodendrocyte precursor cells in the hippocampus. Nature 405, 187-191.

Butt A.M., Duncan A., Hornby M.F., Kirvell S.L., Hunter A., Levine J.M. et al. (1999) Cells expressing the NG2 antigen contact nodes of Ranvier in adult CNS white matter. Glia 26, 84-91.

Butt A.M., Kiff J., Hubbard P. and Berry M. (2002) Synantocytes: new functions for novel NG2 expressing glia. Journal of Neurocytology $31,551-565$.

Chang A., Nishiyama A., Peterson J., Prineas J. and Trapp B.D. (2000) $\mathrm{NG} 2$-positive oligodendrocyte progenitor cells in adult human brain and multiple sclerosis lesions. Journal of Neuroscience 20, 6404-6412.

Chittajallu R., Aguirre A. and Gallo V. (2004) NG2-positive cells in the mouse white and grey matter display distinct physiological properties. Journal of Physiology 561, 109-122. 
Dawson M.R., Polito A., Levine J.M. and Reynolds R. (2003) NG2-expressing glial progenitor cells: an abundant and widespread population of cycling cells in the adult rat CNS. Molecular and Cellular Neuroscience 24, 476-488.

Dimou L., Simon C., Kirchhoff F., Takebayashi H. and Gotz M. (2008) Progeny of Olig2-expressing progenitors in the gray and white matter of the adult mouse cerebral cortex. Journal of Neuroscience $28,10434-10442$.

Engel U. and Wolswijk G. (1996) Oligodendrocyte-type-2 astrocyte $(\mathrm{O}-2 \mathrm{~A})$ progenitor cells derived from adult rat spinal cord: in vitro characteristics and response to PDGF, bFGF and NT-3. Glia 16, 16-26.

ffrench-Constant C. and Raff M.C. (1986) Proliferating bipotential glial progenitor cells in adult rat optic nerve. Nature 319, 499-502.

Fields R.D. (2008) White matter in learning, cognition and psychiatric disorders. Trends in Neurosciences 31, 361-370.

Fortin D., Rom E., Sun H., Yayon A. and Bansal R. (2005) Distinct fibroblast growth factor (FGF)/FGF receptor signaling pairs initiate diverse cellular responses in the oligodendrocyte lineage. Journal of Neuroscience 25, 7470-7479.

Gallo V., Zhou J.M., McBain C.J., Wright P., Knutson P.L. and Armstrong R.C. (1996) Oligodendrocyte progenitor cell proliferation and lineage progression are regulated by glutamate receptor-mediated K+ channel block. Journal of Neuroscience 16, 2659-2670.

Geha S., Pallud J., Junier M.-P., Devaux B., Leonard N., Chassoux F. et al. (2009) NG2+/Olig2 + cells are the major cycle-related cell population of the adult human normal brain. Brain Pathology. Epub in advance of print. Doi 10.1111/j.1750-3639.2009.00295.x.

Hamilton N., Vayro S., Wigley R. and Butt A.M. (2009) Axons and astrocytes release ATP and glutamate to evoke calcium signals in NG2-glia. Glia Epub in advance of print. Doi 10.1002/glia.20902.

Hasan K.M., Kamali A., Kramer L.A., Papnicolaou A.C., Fletcher J.M. and Ewing-Cobbs L. (2008) Diffusion tensor quantification of the human midsagittal corpus callosum subdivisions across the lifespan. Brain Research 1227, 52-67.

Horner P.J., Power A.E., Kempermann G., Kuhn H.G., Palmer T.D., Winkler J. et al. (2000) Proliferation and differentiation of progenitor cells throughout the intact adult rat spinal cord. Journal of Neuroscience 20, 2218-2228.

Karadottir R., Cavelier P., Bergersen L.H. and Attwell D. (2005) NMDA receptors are expressed in oligodendrocytes and activated in ischaemia. Nature 438, 1162-1166.

Karadottir R., Hamilton N.B., Bakiri Y. and Attwell D. (2008) Spiking and nonspiking classes of oligodendrocyte precursor glia in CNS white matter. Nature Neuroscience 11, 450-456.

Keirstead H.S., Levine J.M. and Blakemore W.F. (1998) Response of the oligodendrocyte progenitor cell population (defined by NG2 labelling) to demyelination of the adult spinal cord. Glia 22, 161-170.

Kessaris N., Fogarty M., Iannarelli P., Grist M., Wegner M. and Richardson W.D. (2006) Competing waves of oligodendrocytes in the forebrain and postnatal elimination of an embryonic lineage. Nature Neuroscience 9, 173-179.

Kukley M., Capetillo-Zarate E. and Dietrich D. (2007) Vesicular glutamate release from axons in white matter. Nature Neuroscience 10, 311-320.

Kukley M., Kiladze M., Tognatta R., Hans M., Swandulla D., Schramm J. et al. (2008) Glial cells are born with synapses. FASEB Journal 22, 2957-2969.

Lasiene J., Matsui A., Sawa Y., Wong F. and Horner P.J. (2009) Age-related myelin dynamics revealed by increased oligodendrogenesis and short internodes. Aging Cell 8, 201-213.
Levine J.M. and Reynolds R. (1999) Activation and proliferation of endogeneous oligodendrocyte precursor cells during ethidium bromide-induced demyelination. Experimental Neurology 160, 333-347.

Levison S.W., Young G.M. and Goldman J.E. (1999) Cycling cells in the adult rat neocortex preferentially generate oligodendroglia. Journal of Neuroscience Research 57, 435-446.

Lin S.C. and Bergles D.E. (2002) Physiological characteristics of NG2-expressing glial cells. Journal of Neurocytology 31, 537-549.

Lin S.C. and Bergles D.E. (2004) Synaptic signaling between GABAergic interneurons and oligodendrocyte precursor cells in the hippocampus. Nature Neuroscience 7, 24-32.

Lin S.C., Huck J.H., Roberts J.D., Macklin W.B., Somogyi P. and Bergles D.E. (2005) Climbing fiber innervation of NG2-expressing glia in the mammalian cerebellum. Neuron $46,773-785$.

Mabbott D.J., Noseworthy M., Bouffet E., Laughlin S. and Rockel C. (2006) White matter growth as a mechanism of cognitive development in children. NeuroImage 33, 936-946.

Mao X., Fujiwara Y., Chapdelaine A., Yang H. and Orkin S.H. (2001) Activation of EGFP expression by Cre-mediated excision in a new ROSA26 reporter mouse strain. Blood 97, 324-326.

McTigue D.M. and Tripathi R.B. (2009) The life, death and replacement of oligodendrocytes in the adult CNS. Journal of Neurochemistry $107,1-19$.

Menn B., Garcia-Verdugo J.M., Yaschine C., Gonzalez-Perez O., Rowitch D. and Alvarez-Buylla A. (2006) Origin of oligodendrocytes in the subventricular zone of the adult brain. Journal of Neuroscience 26, 7907-7918.

Nishiyama A., Komitova M., Suzuki R. and Zhu X. (2009) Polydendrocytes (NG2 cells): multifunctional cells with lineage plasticity. Nature Reviews Neuroscience 10, 9-22.

Nowakowski R., Lewin S. and Miller M. (1989) Bromodeoxyuridine immunohistochemical determination of the lengths of the cell cycle and the DNA-synthetic phase for an anatomically defined population. Journal of Neurocytology 18, 311-318.

Ong W.Y. and Levine J.M. (1999) A light and electron microscopic study of NG2 chondroitin sulfate proteoglycan-positive oligodendrocyte precursor cells in the normal and kainate-lesioned rat hippocampus. Neuroscience 92, 83-95.

Pringle N.P., Mudhar H.S., Collarini E.J. and Richardson W.D. (1992) PDGF receptors in the rat CNS: during late neurogenesis, PDGF alpha-receptor expression appears to be restricted to glial cells of the oligodendrocyte lineage. Development 115, 535-551.

Redwine J.M. and Armstrong R.C. (1998) In vivo proliferation of oligodendrocyte progenitors expressing PDGFalphaR during early remyelination. Journal of Neurobiology 37, 413-428.

Redwine J.M., Blinder K.L. and Armstrong R.C. (1997) In situ expression of fibroblast growth factor receptors by oligodendrocyte progenitors and oligodendrocytes in adult mouse central nervous system. Journal of Neuroscience Research 50, 229-237.

Reynolds R., Dawson M., Papadopoulos D., Polito A., Di Bello I.C., Pham-Dinh D. et al. (2002) The response of NG2-expressing oligodendrocyte progenitors to demyelination in MOG-EAE and MS. Journal of Neurocytology 31, 523-536.

Reynolds R. and Hardy R. (1997) Oligodendroglial progenitors labeled with the $\mathrm{O}_{4}$ antibody persist in the adult rat cerebral cortex in vivo. Journal of Neuroscience Research 47, 455-470.

Rivers L., Young K., Rizzi M., Jamen F., Psachoulia K., Wade A. et al. (2008) PDGFRA/NG2-positive glia generate myelinating 
oligodendrocytes and cortical projection neurons in the adult mouse CNS. Nature Neuroscience 11, 1392-1401.

Salter M.G. and Fern R. (2005) NMDA receptors are expressed in developing oligodendrocyte processes and mediate injury. Nature 438, 1167-1171.

Shi J., Marinovich A. and Barres B.A. (1998) Purification and characterization of adult oligodendrocyte precursor cells from the rat optic nerve. Journal of Neuroscience 18, 4627-4636.

Sim F.J., Zhao C., Penderis J. and Franklin R.J. (2002) The age-related decrease in CNS remyelination efficiency is attributable to an impairment of both oligodendrocyte progenitor recruitment and differentiation. Journal of Neuroscience 22, 2451-2459.

Srinivas S., Watanabe T., Lin C.S., William C.M., Tanabe Y., Jessell T.M. et al. (2001) Cre reporter strains produced by targeted insertion of EYFP and ECFP into the ROSA26 locus. BMC Developmental Biology 1, 4 .

Sturrock R.R. (1980) Myelination of the mouse corpus callosum. Neuropathology and Applied Neurobiology. 6, 415-420.

Ullen F., Forsman L., Blom O., Karabanov A. and Madison G. (2008) Intelligence and variability in a simple timing task share neural substrates in the prefrontal white matter. Journal of Neuroscience 28, $4238-4243$.

van Heyningen P., Calver A.R. and Richardson W.D. (2001) Control of progenitor cell number by mitogen supply and demand. Current Biology 11, 232-241.

Vana A.C., Flint N.C., Harwood N.E., Le T.Q., Fruttiger M. and Armstrong R.C. (2007) Platelet-derived growth factor promotes repair of chronically demyelinated white matter. Journal of Neuropathology \& Experimental Neurology 66, 975-988.

Watanabe M., Toyama Y. and Nishiyama A. (2002) Differentiation of proliferated NG2-positive glial progenitor cells in a remyelinating lesion. Journal of Neuroscience Research 69, 826-836.

Wolswijk G. and Noble M. (1989) Identification of an adult-specific glial progenitor cell. Development 105, 387-400.

Woodruff R.H., Fruttiger M., Richardson W.D. and Franklin R.J. (2004) Platelet-derived growth factor regulates oligodendrocyte progenitor numbers in adult CNS and their response following CNS demyelination. Molecular and Cellular Neuroscience 25, 252-262.

Young K.M., Fogarty M., Kessaris N. and Richardson W.D. (2007) Subventricular zone stem cells are heterogeneous with respect to their embryonic origins and neurogenic fates in the adult olfactory bulb. Journal of Neuroscience 27, 8286-8296.

Zahr N.M., Rohlfing T., Pfefferbaum A. and Sullivan E.V. (2009) Problem solving, working memory, and motor correlates of association and commissural fiber bundles in normal aging: a quantitative fiber tracking study. NeuroImage 44, 1050-1062.

Ziskin J.L., Nishiyama A., Rubio M., Fukaya M. and Bergles D.E. (2007) Vesicular release of glutamate from unmyelinated axons in white matter. Nature Neuroscience 10, 321-330.

\section{AUTHORS' ADDRESSES}

Wolfson Institute for Biomedical Research and Research Department of Cell and Developmental Biology University College London

\author{
Gower Street \\ London WC1E 6BT, UK \\ 1 Present address: INRA U1126 \\ UPR 2197 DEPSN
}

CNRS Institut de Neurobiologie Alfred Fessard

Bâtiment 32/33

Avenue de la Terrasse

91198 Gif-sur-Yvette, France

* Joint senior authors

\section{Correspondence should be addressed to:}

William D. Richardson

phone: +442076796729

fax: +44 2072090470

email: w.richardson@ucl.ac.uk

\section{ADDENDUM}

While this paper was in press we learned of another cumulative BrdU study (Hiroko Nakatani and Carlos Parras, Hôpital de la Pitié-Salpêtrière, Paris) similar to our own, which found consistently higher growth fractions than we did: $\sim 90 \%$ in the corpus callosum and $\sim 60 \%$ in the cortex at $\mathrm{P} 80+21$ days BrdU exposure in their study, compared to $\sim 50 \%$ in the corpus callosum and $\sim 40 \%$ in the cortex at $\mathrm{P} 60+21$ in our own study. We explored possible reasons for the discrepancy, including different tissue fixation and BrdU immunolabelling procedures. For example, the Parras group perfusion-fixed their mice with cold $2 \%(\mathrm{w} / \mathrm{v})$ paraformaldehyde (PF) and post-fixed their sections with $4 \% \mathrm{PF}$ for $5 \mathrm{~m}$ just prior to immunolabelling for PDGFRA, whereas we perfused with $4 \% \mathrm{PF}$ followed by $45 \mathrm{~m}$ immersion fixation in $4 \% \mathrm{PF}$, before cutting sections, with no further fixation. In addition, the Parras group pre-treated their sections with $2 \mathrm{M} \mathrm{HCl}$ for $30 \mathrm{~m}$ at $37^{\circ} \mathrm{C}$ prior to BrdU immunolabelling, whereas we used $6 \mathrm{M} \mathrm{HCl}$ for $15 \mathrm{~m}$ at $20-25^{\circ} \mathrm{C}$ (Young et al., 2007). We therefore performed one new cumulative BrdU labelling experiment $\left(\mathrm{P}_{21}+80\right)$ using the Parras fixation and BrdU labelling procedures. From that experiment we estimated the growth fraction of $\mathrm{NG}_{2}$ cells to be $\sim 45 \%$ in both corpus callosum and cortex - roughly in line with our previous estimates (Fig. 1). In parallel, we immunolabelled slides from the Parras lab $(\mathrm{P} 80+21)$ and found that the growth fraction in the cortex was $\sim 75 \%$ in that material. From this it appears that the difference might reside in the tissue (e.g. the mice colonies) rather than the preparation procedures. This requires further investigation, but at present we stand by the growth fraction estimates presented in our present paper. Our conclusion that the NG2 cell cycle lengthens dramatically with age is unaffected by these issues, although actual cell cycle lengths at all ages might be longer than we estimated. We thank Drs. Parras and Nakatani for drawing our attention to this discrepancy and for helping us try to resolve it. 